It may be as well to state here that I hold with Niemeyer that, " in the present stage of science, there is but one kind of tubercle-miliary tubercle, and but one form of tuberculosis-miliary tuberculosis."

Niemeyer indicates in his lectures on Phthisis that the temperature-curves in that disease are almost as regular as in typhoid fever or acute pneumonia. I cannot, however, find, either in his book or in Wunderlich's (translated by the Sydenham Society), any very distinct guide as to the type of temperature in acute tuberculosis, nor do I see how there can be much uniformity. The extent and type of the tuberculosis seem to modify the temperature very considerably. So much is this the case that Wunderlich states that when tubercles occur in patients suffering from advanced phthisis, pneumonia, or cerebral disease, they sometimes fail to affect the temperature at all, or that at least their influence is very slight. Dr. Woodman, his translator, also expresses his conviction that in some cases miliary tuberculosis does not affect the temperature at all. This opinion is certainly opposed to the statement of Niemeyer, and to the experience of Dr. Sidney Ringer as stated in his book on the Temperature in Phthisis, and to my own so far as my limited observation of the temperature in these cases goes. I can only barely imagine the absence of any rise of temperature as occurring in cases of localised secondary tuberculosis with scanty deposit. The general conclusion of most observers seems to be, that, in primary tuberculosis, the more acute the pyrexia, and the more closely it approaches to the remittent type, the greater is its resemblance to enteric fever; but that in tuberculosis the temperature wave is less regular and less high, and the remissions greater. The absence of rose-coloured spots is not to be depended on in the diagnosis, as they are certainly not always present in enteric fever.

In these two cases the absence of cheesy masses in the lungs and other organs tends to disprove the theory, first advanced by Buhl and since accepted by various writers, that acute tuberculosis is a secondary process, the result of infection produced by the absorption of substances which have undergone caseous metamorphosis.

There can be no doubt, from numerous recent observations, that the miliary tubercles are situated in the connective tissue of the lung, in very intimate relation with the bloodvessels, and not in the alveoli. The alveoli may become blocked; but in uncomplicated cases this effect is produced by pressure and the swelling of their walls, and not by exudation (Rindfleisch). It is long since Virchow, in his "Cellular Pathology," pointed out the lymphoid nature of tubercle, and the very close resemblance of the cells of the tubercle granule with the corpuseles of the lymphatic glands: but it is a question whether the tubercles derive their origin solely from the lymphatic system, as propounded by Klebs, so as to be called the result of a lymphangitis.

Aberdeen.

\section{SUCCESSFUL TREATMENT OF A CASE OF TETANUS.}

\section{By J. B. CARRUTHERS, M.D.}

THE pathology of tetanus and the most effectual remedy for that disease are yet undetermined questions in medical science. The peculiar character of the disorder and the post-mortem examinations have revealed as jet almost yothing; consequently our treatment of it must be purely empirical. Many drugs of directly opposite action have occasionally been used with apparent success in some instances of this disease. In estimating the effect of remedies, their action should always be noted, and, when beneficial, persevered in and recorded. And as there may be some facts in the following very acute case, which recently occurred in my practice, which may prove interesting to the profession-some novelty in the treatment, and ultimately a good recovery, - I beg to offer a short account of it, as its publication appears to me to be as desirable as, on behalf of science, it may be interesting. Having previously been convinced of the therapeutic value of chloral in combating the involuntary movements of chorea, $I$ in this case wish to allude to its action combined with bromide of potassium in tetanic spasms, and with astonishingly good effect.

The patient, J. H-, aged fourteen years, a boy at school, of an active and restless disposition, had always enjoyed good health. In the end of the first week of April he got bis little-finger bruised and lacerated from a piece of iron falling on it. The finger healed satisfactorily, the nail coming away afterwards. On the 18th April, he and a companion were attempting to scale a high wall; being unsuccessful in their efforts, his companion, with heavy nailed boots, mounted on the shoulders of $\mathrm{J}$. H- and in consequence of the difficulty of ascending the wall, he trod severely on his shoulders-so much so that he complained more or less of pain there afterwards. Next day he was kicked on the back in an encounter with some other boys, but he was very chary about letting this out, as he rather got the worst of $i t$.

On the 24th April, the first day I saw him, he was very feverish, a pulse of 100 , with pain on pressure over both scapular regions, for which I ordered anodyne fomentations. On the following day the symptoms were much the same, he having passed a restless night.

On the morning of the $26 \mathrm{th}$ he was seized with tetanic spasms, and rigidity of the muscles of the whole body, with most acute pain over the entire length of the spinal column, so much so that the least pressure with the finger on it was almost unbearable, and in fact brought on opisthotonos. As I now viewed the case as one of considerable medical interest, I asked Dr. T. Keith, of Edinburgh, to see the patient along with me. At our interview the tetanic spasms were most severe, and as the spinal pain had, if anything, increased, we injected twenty minims of nepenthe into his back, and ordered a dozen leeches to be applied over the seat of pain, and ten grains of chloral to be given every three hours in syrup and water. At 9 the same evening Dr. Warburton Begbie saw the patient along with us. The pain over the spine was now greatly relieved, but he was very restless. Pulse 130 ; temperature $102 \cdot 2^{\circ}$; his jaw closed; the muscles of his abdomen and legs very rigid; his face livid; his skin warm, and covered with profuse perspiration. We all viewed the case as one of great anxiety, both from its acuteness and suddenness of attack, as well as from the gravity of the disease. The treatment now was restricted to ten grains of chloral hydrate and twenty grains of bromide of potassium in syrup and water every three hours, and to be watched with great care and quietude.

I may here state that Drs. W. Begbie and T. Keith took special interest in the case, freely giving me their valuable opinions on the salient points as they presented themselves during the treatment.

On April 27 th at 10 A.M. I saw the patient, and found he had had a very restless night; was scarcely a quarter of an hour quiet during the whole night. Complains of some pain in his back, and of the burning of his tongue from the chloral; nevertheless the medicine was given during this and the following day every two hours. Pulse 122 ; temperature in the mouth $102^{\circ} 1^{\circ}$. Swallows milk pretty well when the tube of the cup is pushed into the side of his mouth.

April 28th.-10 A.M.: Had four hours' sleep during the night. The muscles of his legs softer and the tetanic spasms not so violent. As the pain over his spine still continued, a strip of belladonna plaster was applied over its entire length. At the time of my visit, the effort of swallowing his medicine, the taste of which he dreaded, brought on a paroxysm. In the evening of the same day an enema of castor oil and warm water was given, and the action of chloral was now distinctly seen in the congestion of his eyes.

29th.-10.30 A.m.: His bowels acted satisfactorily from the enema; had some hours' quiet sleep during the night, and on the whole his symptoms were alleviated.

30 th. - 10 A.m. : Slept well during the night. Has still fits of spasms frequently, but they are less easily brought about. Pulse 108 ; temperature $101 \cdot 2^{\circ}$.

May 1st. - 10 A.m.: Passed a good night. The muscles of the legs now much relaxed, but the rigidity of the recti abdominis and masseter continues. At 5 P.M., as Dr. W. Begbie and $I$ entered the room, he had just awoke out of a sleep. The start at our entering brought on a spasm, which soon passed off, and he took a good drink of milk from the 
cup, which I may here state was his chief food during his whole illness.

2nd.-10 A.M. : Gradually improving. Slept well during the night. Can open his mouth about a quarter of an inch to-day. Has occasional attacks of pain and spasm, which only lasted a minute or two.

3rd.-10 A.m.: Newly awoke from sleep. Was very excitable and talkative, and replied, in answer to my question, that he was perfectly well, except the pain in his back. Pulse 100; temperature $101^{\circ}$.

4th.-Progressing satisfactorily. At 5.50 P.M. Drs. Begbie and Keith expressed themselves satisfied with his general improvement.

5th.-10 A.M. : Had a good night's sleep. Pulse 96 ; temperature $101^{\circ}$. About 7 P.M. I was sent for hurriedly, as he had a severe tetanic spasm affecting his throat on a wakening from sleep. When I saw him he had marked opisthotonos, and as it passed off he suffered from laryngeal symptoms of dyspncea with phlegm, which were very distressing.

6th.-Passed a restless night, and had several tetanic seizures. At our interview in the evening he was so much weaker from the return of the spasm that we thought it advisable to give him a tablespoonful of port wine every three hours.

7th. -10 A.M.: Had a good night's sleep, and is really well, only slightly weaker.

8th.-10 A.M. : Had several hours' sleep during the night and occasional spasms. In the evening he was again seized with laryngeal spasms with dyspnca, which soon passed off after he had ejected some phlegm.

From this date the patient gradually progressed towards recovery. On the evening of May 10th the spasms were so mitigated, and the action of the chloral was so marked in his system, that we agreed to stop it, only giving the bromide in ten-grain doses every three hours, which we gradually diminished to three times daily till we discontinued it also. On the 18th May he was able to open his mouth, put out his tongue for the first time, and eat a biscuit and some meat, which he relished.

The noteworthy feature in the treatment of this case is the quantity of chloral taken by the patient, he having taken 1140 grs. in sixteen days (equal to fully 71 grs. a day) in a most acute attack of tetanus, with the result of the spasms leaving him on May 12th, exactly eighteen days from the date of seizure; while in their place the peculiar action of the medicine showed itself in a variety of ways. All kinds of delusions ensued. The boy often imagined he saw strange objects in the room, such as carriages, ships, robbers, \&c. He was even allowed to keep pistols beside him to quiet him. At one time he was talking, at another time smiling, at another time crying, and at another time fighting, \&c. His mind wavered very much, so much so that he did not know his father. When told that his father was beside him, he said, "That man is an impostor, and will be punished; he has just come from a railway station, and I would like to shoot him." At another time he started up at the sight of his father, and called him "Mr. Pretender." One day he called out, "There is a ship sailing round the room with cream and biscuit," and having recently eaten a biscuit he asked for another to keep it company. Another day he imagined he was fixed in a tree with his head stuck in the branches. The same day he was engaged fighting a battle, and said he would not leave till the last, and cried out, "Save that boy; they are kicking him too severely." Often he could not be persuaded he was in his own room and bed, and continually exclaimed, "Carry me home - carry me home to my own bed." Another day he fancied he saw his father's master enter a carriage with liveried servants, and cried out, " $\mathrm{He}$ must have been left a fortune lately, from the number of horses and carriages he has." One day he thought he was swimming in the Firth of Forth to the island of Mickery, and begged of his aunt to blow up the swimmingbladder under his arms, otherwise he would sink. A few minutes afterwards he said it was all imagination. The same day he said he was sailing in the boat to Fife to visit his friends, and remarked what jolly fun he would have. He imagined various characters were in his room; but latterly he of ten wept bitterly at being so foolish as to believe his own imagination. It is perhaps not unworthy of record that as his delusions lessened he seemed to remember afterwards what he saw and did, and wept nervously on that account. A susceptibility to form impressions, and a quickness and fertility of imagination, appeared to me to characterise all his actions. These delusions continued in many forms and varieties, but gradually lessened, till the 25th of May, when they finally ceased, and the patient is now convalescent.

The principal point of interest in this case is its acuteness, accompanied as it was with severe spinal pain. Perhaps it may be a matter of opinion what was the primary exciting cause of the tetanus. Undoubtedly it was traumatic, and probably due to the bruised little finger. But it appears to me that the attack of acute spinal disorder from which he suffered at the commencement of his illness could only have resulted from one or other of the injuries to his back.

As regards the treatment, the marked amelioration of the symptoms on the third day after the chloral hydrate and bromide of potassium were given shows considerable effi. cacy in favour of these drugs in subduing the spasms. At the first the case was as disheartening as any case could well be, but by steady perseverance in the treatment the convulsions gradually weakened until they altogether ceased, and, finally, the patient got well. Although in some particulars this case may deviate from the usual professional groove of practice, $I$ think it should furnish an interesting and not unuseful page in the history of chloral in connexion with the treatment of that formidable disease, tetanus. I was much struck with the remedial effect produced by it in my little patient, whose life at one time was in extreme danger. As narrated by Dr. Reynolds, "the mind wanders much after a single large dose of chloral," and true to this peculiarity of the medicine in my case, where the quantity administered was very large, though cautiously and gradually administered, the delusions were in proportion multiplied and intensified, thus plainly establishing both the physiological and therapeutical action of the medicine.

I have, in conclusion, to acknowledge with thankfulness the services of Drs. W. Begbie and T. Keitb, who, with true generosity, often visited with me my little patient, and not only stated their opinion as to the peculiar and formidable character of the case, but also concurred with me as regards the treatment adopted.

Edinburgh.

\section{CASE OF SNAKE-BITE :}

A TAMIL WOMAN FAR ADVANCED IN PREGNANCY BITTEN BY A TIC POLONGA; RECOVERY OF THE MOTHER AND DEATH OF THE CHILD.

By J. MULVANY, Staff-SuRg. R.N.

The following case offers some points of general and physiological interest.

The wife of the steward of the Naval Hospital at Trincomalee, a young and vigorous woman about twent5-six years of age, the mother of four children, and far advanced in her fifth pregnancy, was bitten on the dorsum of the right foot at $5.30 \mathrm{A.M}$. on the 30 th of October last by the terrible tic polonga of Ceylon. She shouted lustily, and her busband, running to her assistance, tied a string tightly round the calf of the leg, and then ran for the "snake doctor." The pain was intense from the outset, and in fifteen minutes violent convulsions supervened, and she took to ber bed. In an hour and $a$ half the native doctor arrived, and applied a snake stone to the wound. Numbness now set in about the foot and gradually travelled upwards to the body. She became unable to see, and at 10 o'clock was insensible. The stone remained adherent four hours, and fell off at 11 A.M. Being acquainted with her husband, I readily obtained permission to watch the case, but could not offer assistance, as her caste did not permit her to receive any from me. She remained in a state of coma up to 4 P.Mr., and by this time her foot and leg as far up as the knee became considerably swollen, and there was a serous oozing from the puncture on the dorsum of the foot. The pulse was of good volume, but slightly diminished in frequency. She lay on her back, with the eyelids closed. The pupils were contracted, but relaxed slowly when exposed to light. The skin was cool everywhere, except the forearms, which, though uncovered, 